the uniaxial case. The greater plane-strain compressive strength of columnar-grained ice, when the loading and confining directions are in the plane of the ice cover, can be attributed to its anisotropic structure, which leads to a different failure mechanism for the plane-strain case.

This paper is published in full in Journal of Glaciology, Vol. 18, No. 8o.

\title{
DISGUSSION
}

P. R. KRY : Do you think a lubricant such as silicone oil would reduce friction on the side restraining plates?

R. Frederking: Kerosene and some other light oils reduced the friction. We did not test silicone oil.

A. J. Gow: You mentioned that you used columnar ice with horizontal $c$-axes. Did you attempt to manufacture ice samples with $c$-axes vertical? In our studies of lake ice in New Hampshire we found that the $c$-axis vertical structure is much more common than the $c$-axis horizontal structure.

Frederking: No, we could grow ice with horizontal $c$-axes in the laboratory but could not make reproducible samples with vertical $c$-axes.

J. W. Glen: In your graph for granular-snow ice the curves for uniaxial and confined strengths crossed, implying that in some range confined strength is less than unconfined. Do you believe this represents a real situation? Surely unconfined strength must always be lower.

Frederking: This is an artefact of our least-squares fitting method. It may be significant that the curves approach each other at the low strain-rates.

\section{BEARING CAPACITY OF FLOATING ICE SHEETS}

\author{
By M. D. Coon \\ (University of Washington, Seattle, Washington 98 г 03 , U.S.A.)
}

Abstract. Floating ice sheets are loaded thermally as well as mechanically by winds, water currents, and at times by man-made structures. When floating ice sheets are to be used in engineering problems, all of the applied loads must be accounted for. Determining the forces that will cause an ice sheet to fail is difficult not only because of the various kinds of loads, but also because the properties of ice sheets (fresh and sea) are dependent upon many variables, and the properties vary through the thickness of the ice sheet.

To illustrate the bearing-capacity problem, the equations for a beam are considered, including an example of the variations of ice properties through the thickness of an ice beam. The physical behavior of the ice enters the problem through two systems of equations: one which relates the force and deformation of an ice sheet, and the second which is a statement of the stress state which will cause the ice sheet to fail. A full understanding of how the equations depend on such variables as temperature and brine volume are crucial to an understanding of how the applied loads cause the ice sheet to fail. 


\section{DISCUSSION}

S. F. AckLey: Is there any indication that the crack running through the main AIDJEX Camp is related to the load induced by the presence of the camp or is primarily induced by external geophysical forces?

M. D. Coon: The camp must have added to the existing geophysical stresses in the ice, but to say that the camp caused the crack is very questionable.

J. W. GLEN: While of course agreeing with your reply to Dr Ackley, is it true that the presence of a camp markedly increases the probability that a fracture will pass through the camp area? By now there have been quite a large number of camps on ice. Does the record of cases of fractures through the camp indicate a more-than-random chance suggesting the presence of the camp attracts a crack?

Coon: I do not believe this sort of information on experience with camps on ice has been collected, so it is difficult to definitely say that a camp increases the likelihood of a crack passing through that era.

O. Orheim: I do not think we should dismiss off-hand the possibility that the extra loading can influence the location of the crack. There are other Arctic examples (e.g. Wally Herbert's camp) of sea ice cracking at a camp location. And even the Antarctic ice shelves have calved through a station, for example Little America V and Camp Michigan. It seems possible that the extra load here, too, may have influenced the location of failure. The load in these cases is of course not just the station, but chiefly the snow dome that will have been built up.

P. R. KRY: Do you have a comment on the complexities of defining a strength distribution through an ice sheet (particularly a brackish or fresh ice sheet) with tests on small samples for which strength may depend significantly on sample-to-crystal size ratio?

Coon: There are problems with scale effects in small-scale tests, but these effects can be experimentally investigated.

D. V. REDDy: Are there any references to in-plane elasto-plastic deformation fields for ice sheets impacting structures?

Coon: There are analogous solutions in the literature but none of them have been specifically applied to ice.

D. E. Nevel: In your talk you mentioned the problem of the strength depending upon the biaxial stress state. Recent papers by Haynes (1973) and Nevel and Haynes (1976) have confirmed this fact in the compression-tension quadrant. Data in the tension-tension quadrant would be more important for bearing-capacity problem. Do you know of any such strength data?

In addition, uniaxial-creep tension tests have been performed by Burdick ([$\left.\left.{ }^{c} 1976\right]\right)$. His results show that the stress level and the time of creep effect the strength. At first the strength decreased, but later under large creep deformations, the strength increases.

Coon: I know of no tension-tension ice test data but agree this will be very important in bearing capacity problems.

\section{REFERENCES}

Haynes, F. D. 1973. Tensile strength of ice under triaxial stresses. U.S. Cold Regions Research and Engineering Laboratory. Research Report 2 I 3.

Nevel, D. E., and Haynes, F. D. 1976. Interpretation of the tensile strength of ice under triaxial stress. U.S. Cold Regions Research and Engineering Laboratory. Report 76-5.

Burdick, J. [ [ ${ }_{1}$ 1976.] Tensile creep-rupture of ice. (In Proceedings of the third International Conference on Port and Ocean Engineering under Arctic Conditions held in Fairbanks, Alaska, University of Alaska, 11-15 August 1975. Vol. I. Fairbanks, Alaska, Institute of Marine Science, University of Alaska, p. 235-46.) 